\title{
DERECHO Y POLÍTICAS AMBIENTALES EN EL PAÍS VASCO (PRIMER SEMESTRE 2021)
}

\author{
IÑIGO LAZKANO BROTÓNS \\ Profesor colaborador \\ Universidad del País Vasco / Euskal Herriko Unibersitatea
}

SUMARIO: 1. Introducción general. 2. Reorganización administrativa. 3. Aprobación de planes de ordenación territorial. 4. Protección de Gaztelugatxe como bien de interés cultural. 5. Reglamento de sostenibilidad energética. 6. Pesca. 7. Actividad administrativa de fomento.

\section{Introducción general}

Período sin grandes cambios ni novedades significativas, a la espera de la aprobación parlamentaria de las nuevas leyes de administración ambiental y de conservación de la naturaleza.

Dentro del catálogo de nuevas normas incluido en el calendario legislativo, se ha procedido a aprobar de manera previa y a someter a información pública el Anteproyecto de Ley de Movilidad Sostenible (Resolución de 14 de abril de 2021, BOPV 77, 21 de abril).

\section{Reorganización administrativa}

En desarrollo de la nueva organización administrativa departamental operada en el Gobierno Vasco, se han dictado los decretos de estructura orgánica de los dos departamentos que retienen las funciones más relevantes con incidencia ambiental.

Por un lado, el Decreto 68/2021, de 23 de febrero, establece la estructura orgánica y funcional del Departamento de Desarrollo Económico, Sostenibilidad y Medio Ambiente (DDESMA)(BOPV 47, 5 de marzo). Dentro de los órganos centrales del departamento hay que referirse principalmente a la existencia de la Viceconsejería de Sostenibilidad Ambiental, dividida en dos direcciones: una de Calidad Ambiental y Economía Circular y otra de Patrimonio Natural y Cambio Climático. La primera se ocupa de la ordenación, 
evaluación, vigilancia, inspección y control de las actividades con incidencia en el medio ambiente, de la protección de la atmósfera, de la prevención y corrección de la contaminación del suelo, de la evaluación ambiental, de la responsabilidad y disciplina ambiental y de la economía circular; y la segunda de la planificación de la política ambiental, de la protección del patrimonio natural, de la garantía y fomento del desarrollo sostenible, del cambio climático y de la información, participación, sensibilización, educación y formación ambiental.

También en otras viceconsejerías se incardinan determinadas funciones con incidencia en lo ambiental, como lo relativo a la transición, sostenibilidad y eficiencia energéticas (en la Viceconsejería de Industria) o lo referente a la protección de los animales, la caza, la pesca y el marisqueo o la ordenación forestal (en la Viceconsejería de Agricultura, Pesca y Política Alimentaria).

Como órganos periféricos del departamento se hallan los Servicios Territoriales de Sostenibilidad Ambiental y el Servicio de la Reserva de la Biosfera de Urdaibai, adscribiéndose como entidades del sector público adscritas, entre otros, entes públicos de derecho privado como el Ente Vasco de la Energía (EVE) o la Agencia Vasca del Agua (URA) y sociedades públicas como el Instituto Vasco de Investigación y Desarrollo Agrario (NEIKER) o la Sociedad Pública de Gestión Ambiental (IHOBE). Se adscriben también al DDESMA determinados órganos colegiados con funciones directa o indirectamente ambientales: la Mesa de los Áridos, la Comisión de Sostenibilidad Energética, la Mesa de Sanidad Forestal, el Consejo Agrario y Alimentario, la Comisión de Política Agraria y Alimentaria, el Comité Consultivo de Pesca y, sobre todo, la Comisión Ambiental del País Vasco, el Consejo Asesor de Medio Ambiente, el Patronato y el Consejo de Cooperación de la Reserva de la Biosfera de Urdaibai y el Consejo Asesor de Conservación de la Naturaleza.

Previamente a la aprobación de dicha estructura departamental se había operado una reforma menor en la configuración del departamento en virtud del Decreto 48/2020, de 28 de diciembre (BOPV 262, 31 de diciembre), de modificación de la norma de creación, supresión y modificación de departamentos. Mediante esta norma el área de actuación "protección de los animales", que antes se hallaba inserta en el Departamento de Igualdad, Justicia y Políticas Sociales, pasó a formar parte del ámbito competencial del DDESMA, por entender dicha área más adecuada y sinérgica con el conjunto de funciones y áreas de actuación atribuidas a este último. 
Además, por Orden de la Consejera del DDESMA, se han delegado en la Viceconsejera competente en el área de medio ambiente la imposición de las sanciones graves y leves previstas en la Ley General de Protección del Medio Ambiente de 1998, de las sanciones graves previstas en la Ley para la Prevención y Corrección de la Contaminación del Suelo de 2015, así como la resolución de los recursos de alzada contra las resoluciones de la Dirección General de la Agencia Vasca del Agua (URA).

Por su parte, el Decreto 11/2021, de 19 de enero, establece la estructura orgánica y funcional del Departamento de Planificación Territorial, Vivienda y Transportes (DPTVT) (BOPV 21, 29 de enero). En este caso resulta de particular interés referirse a su Dirección de Planificación Territorial y Agenda Urbana (integrada en la Viceconsejería de idéntica denominación), entre cuyas áreas de actuación figuran la agenda urbana, la ordenación del territorio y paisaje, la información territorial o el suelo y el urbanismo. También se adscriben a este departamento órganos colegiados que desarrollan competencias en materias muy próximas, cuando no solapadas, a la protección ambiental, como la Comisión de Ordenación del Territorio, el Consejo Asesor de Política Territorial o la Comisión de Coordinación de la Información Geográfica del sector público.

\section{Aprobacion de planes de ordenación territorial}

No ha habido demasiadas novedades en la implementación del planeamiento territorial. Se ha aprobado definitivamente la modificación del PTP del área funcional de Donostialdea-Bajo Bidasoa, relativa a las determinaciones del paisaje (Decreto 154/2020, de 22 de septiembre; BOPV 209, 23 de octubre).

Por Orden de 22 de marzo de 2021, de la Consejera del DDESMA, se ha acordado también el inicio del procedimiento para la elaboración de un Plan Territorial Sectorial de las energías renovables en Euskadi (BOPV 64, 30 de marzo). Los objetivos finales del plan son claros y obvios: contribuir a la descarbonización de la producción energética, favorecer una mayor independencia energética, impulsar el desarrollo de la economía circular, etc. La elaboración de este plan se debe, normativamente hablando, a las exigencias de la Ley de Sostenibilidad Energética, de las Directrices de Ordenación Territorial, así como a varias decisiones instadas por el Parlamento Vasco. Acompaña al plan un programa de participación ciudadana, que diseña un proceso participativo como 
mecanismo de concertación pública para definir de formal social y participada las bases del nuevo modelo territorial de energías renovables para Euskadi.

\section{Protección de Gaztelugatxe como bien de interés cultural}

Una de las decisiones más significativas adoptadas durante el período de referencia es la declaración de San Juan de Gaztelugatxe (sito en Bermeo, Bizkaia) como Bien Cultural de Protección Especial, con la categoría de Paisaje Cultural (Decreto 125/2021, de 13 de abril; BOPV 70, 23 de abril). La declaración es la consecuencia de (y la manera de afrontar) los problemas generados por una atracción recreativo-turística masiva de público, derivada de la inclusión de imágenes de de la zona en una exitosa serie de televisión.

El área de Gaztelugatxe ya estaba protegida medioambientalmente, desde 1998, bajo la categoría de biotopo protegido. Pero este tipo de espacio protegido no exige, en la vigente legislación autonómica vasca, la aprobación de un previo plan de ordenación de recursos naturales. Las normas reguladoras de los diferentes usos venían directamente establecidas en el decreto de declaración, y resultaban ser unas normas muy exiguas de carácter prohibitorio total (en materia de vertidos, acampadas, uso de fuego, edificaciones e introducción de especies) o en función de determinadas modalidades o plazos (sobre pesca, marisqueo, extracción de recursos naturales, fondeo de embarcaciones, caza, buceo, etc.). Aunque es cierto que también se atribuía al órgano gestor del espacio natural (la Diputación Foral de Bizkaia) la posibilidad de establecer medidas de protección adicionales para la defensa, conservación y restauración del medio natural del biotopo. Por otra parte, San Juan de Gaztelugatxe es, a su vez, una zona de especial conservación (ZEC) de la Red Natura 2000 (ES2130005), contando con unas medidas de conservación desde 2013. Estas medidas se plasman en unas directrices y regulaciones específicas, que no se ciñen a los límites concretos de los espacios Natura 2000 sino que son de aplicación a un ámbito mayor (en el caso de Gaztelugatxe, la extensión del biotopo y su zona periférica de protección), y que se refieren, entre otros aspectos, a infraestructuras, usos edificatorios, usos públicos, actividades recreativas y limitaciones de acceso. De hecho se prevé específicamente que las administraciones competentes puedan establecer directrices y regulaciones del uso público mediante planes específicos que atenderán al régimen preventivo establecido en el art. 45 de la Ley del Patrimonio Natural y la Biodiversidad. 
El nuevo Decreto 125/2021 añade, por lo tanto, una mayor densidad normativa a la ordenación de esta área, lo cual puede estar justificado (y lo está) si se trata de profundizar en la protección de los elementos artificiales (la ermita, la escalinata de acceso, el puente, etc.) desde la perspectiva jurídico-cultural. Pero también puede dar lugar a contradicciones y problemas, desde el momento en el que la mentada regulación aborda también elementos naturales, difícilmente separables en cuanto objeto de protección de las medidas estrictamente medioambientales. En efecto, en el Decreto 125/2012, junto a la protección del área monumental (zona 1), hay una zona 2 (con ámbitos terrestre y marítimo) en la que predomina exclusivamente el valor ambiental y paisajístico de la zona. De tal forma que, además de incluirse dentro de los bienes culturales protegidos de la zona 1 determinados "espacios abiertos" no construidos, en los que ha de preservarse fundamentalmente su carácter natural (y para ello se fijan algunos criterios de intervención que se solapan con los fijados en la normativa ambiental), también se establece un régimen específico de protección aplicable a la zona 2, curiosamente sin ninguna referencia a la normativa ambiental señalada (salvo en lo que se refiere al medio marino y a la incidencia de la normativa de costas).

\section{Reglamento de sostenibilidad energética}

Por Decreto 254/2020, de 10 de noviembre, sobre sostenibilidad energética de la CAPV (BOPV 229, 18 de noviembre) se ha desarrollado la ley que, sobre esta materia, se dictó en 2019. Este reglamento de desarrollo pretende cubrir determinados vacíos legales detectados y resolver dudas interpretativas en la aplicación del texto legal. En concreto, los objetivos del decreto son aclarar el alcance de las obligaciones previstas en la norma legal (en especial en cuanto a plazos de remisión de información, de elaboración de informes y planes, de exigencia de certificaciones, etc.), precisar algunos conceptos jurídicos indeterminados (por ejemplo, incorpora aclaraciones a conceptos definidos legalmente: auditor o auditoría energética, empresa proveedora de servicios energéticos, energía renovable, sistema de gestión energética o sistema de gestión energética certificado) y regular la composición y funcionamiento de la Comisión para la Sostenibilidad Energética del Sector Público de la CAPV. El decreto desarrolla las previsiones de todos los títulos y de varias disposiciones de la ley, con la excepción de las medidas regulatorias para alcanzar la sustitución de los hidrocarburos líquidos, antes del 31 de diciembre de 2030, por otras energías más respetuosas con el medio ambiente, las cuales serán objeto de desarrollo reglamentario independiente.

\section{Pesca}


Por Orden de 19 de octubre de 2020, de la Consejera de DDESMA (BOPV 213, 28 de octubre) se ha establecido la clasificación de las zonas de producción de moluscos del litoral de la CAPV.

\section{Actividad administrativa de fomento}

En relación a la actividad de fomento desplegada durante el período que estamos analizando en esta crónica, hay que reseñar la convocatoria por el DDESMA de las ayudas a la promoción y desarrollo de las zonas litorales de la CAPV (Programa Itsaspen), llevada a cabo por Orden de 10 de febrero de 2021 (BOPV 38, 22 de febrero), uno de cuyos objetivos subvencionables es la conservación y mejora del patrimonio litoral; y de las ayudas agroambientales a la diversificación de cultivos extensivos bajo técnicas de producción agrícola sostenible, por Orden de 31 de marzo de 2021 (BOPV 73, 15 de abril). 